\title{
FFR-Guided Versus Coronary Angiogram Guided CABG: A Systematic Review and Meta-Analysis
}

\author{
Dhayan Timbadia ${ }^{1}$, Ashlynn Ler ${ }^{2}$, Faizus Sazzad ${ }^{3}$, CHRISTOS ALEXIOU ${ }^{4}$, and \\ Theodoros Kofidis ${ }^{5}$ \\ ${ }^{1}$ National University Singapore Yong Loo Lin School of Medicine \\ ${ }^{2}$ National University of Ireland Galway School of Medicine \\ ${ }^{3}$ National University Heart Centre \\ ${ }^{4}$ Interbalkan European Medical Centre \\ ${ }^{5}$ Affiliation not available
}

April 28, 2020

\begin{abstract}
Background Fractional flow reserve (FFR) is a well-established method for the evaluation of coronary artery stenosis before PCI. However, whether FFR assessment should be routinely used before CABG remains unclear. Our aim was to compare the outcomes of using FFR with that of conventional CAG (coronary angiography) in guiding CABG. Method This systematic review and meta-analysis was performed according to the PRISMA guidelines. Six studies were included, of which four were double-arm (two prospectively randomised) and two single-arm, reporting data on 1931 patients. A meta-analysis was done for double-arm studies, comparing rates of overall death, MACCE, target vessel revascularisation, spontaneous MI and graft patency. The data of all six studies were entered in a pooled analysis for the endpoints of overall death, spontaneous MI and target vessel revascularisation. Results Meta-analysis demonstrated significantly lower death rates in the FFR-guided than the CAG-guided group $(\mathrm{p}=0.03)$ and no significant differences in the rates of MACCE, target vessel revascularisation, spontaneous MI and graft patency. In pooled analysis, FFR-guided group was linked with lower rates of overall death and spontaneous MI. Graft occlusion rate was significantly lower after FFR in one retrospective study, however, this difference was lost in meta-analysis $(\mathrm{p}=0.24)$. Conclusion In this meta-analysis, FFR-guided CABG was associated with lower overall death rate and was, at least, non-inferior in the endpoints of MACCE, target vessel revascularisation, spontaneous MI and graft patency than CAG-guided CABG. Further randomized trials are needed to define the role of FFR in guiding CABG surgery.
\end{abstract}

\section{Statistical analyses}

Forest plots for double-arm studies were generated using RevMan 5.3 ${ }^{10}$. All meta-analyses were carried out using fixed-effects models and risk ratios were calculated. Pooled data analyses were carried out using OpenMeta[Analyst] software ${ }^{11}$. The outcomes were pooled using random-effect model. Weighed pooled rates were calculated with confidence intervals.

\section{Results}

Study selection

The systematic search revealed a total of 5843 papers. After duplicates were excluded, 3435 papers remained for review. Based on title and abstract review, irrelevant publications for those that did not satisfy our inclusion criteria were not considered, leaving $9 \operatorname{articles}^{6,12-19}$ for full-text review. Following the full-text assessment of these articles, studies that lacked data on outcomes of FFR guided CABG, or which did not meet our inclusion criteria were excluded (Figure 1) leaving a total of 6 articles $^{12-17}$ to be analysed. 
Quality of evidence

Through our risk of bias assessment of the included studies, we determined that evidence of the 2 randomized controlled trials were of robust quality, with no severe risk of bias associated with the design of the studies ${ }^{12,13}$ (Figure 2). For the observational studies ${ }^{14-17}$, apart from high risk of bias in confounding factors and patient selection that are typical of studies with retrospective nature, we determined that the evidence provided by these studies (and the included studies overall) was still of an acceptable quality (Table 1).

Of the 6 included studies, 2 were randomised control trials ${ }^{12,13}$ and 4 observational studies ${ }^{14-17}$. In 2 of the observational studies ${ }^{16,17}$ included were only participants who underwent FFR-guided CABG (single-arm studies). The data from these studies was used to carry out a pooled analysis.

Basic Demographics

The majority of patients undergoing CABG were males in their sixties. There were no significant differences between FFR guided CABG and CAG guided CABG patients in any of the reported baseline characteristics (Table 2) except for in the study Toth et $\mathrm{al}^{15}$ where the patients in the CAG guided group were older $(P<$ $0.001)$ and more frequently female $(P=0.010)$ and diabetic $(P=0.034)$. In the same study ${ }^{15}$, the patients in the FFR guided group more frequently had PCI in the past $(P<0.001)$.

Basic graft characteristics

There were several significant differences in terms of baseline graft characteristic between the FFR guided CABG group and the CAG guided CABG group (Table 3 ). In the observational study by Toth et al ${ }^{15}$ there were significantly more arterial anastomoses $(P<0.001)$ and significantly less venous anastomoses $(\mathrm{P}<$ 0.001) in the FFR group than in the CAD-guided CABG group. Also, in the randomised study by Toth et al 2019, there were significantly more venous anastomoses per patient in the CAG-guided CABG group $(\mathrm{P}=0.031)$.

Overall death (double-arm randomised and observational studies)

Comparing the results of two randomised control studies ${ }^{12,13}$ with a total of 269 patients, we noted no significant difference in overall death rate between the FFR-guided CABG as compared to CAG guided CABG (RR: 0.86, 95\% CI: 0.19 to 3.95, $p=0.85$ ) (Figure 2A). Analysing the data of two double-arm observational studies ${ }^{14,15}$ and 1023 patients we observed significantly lower rates of overall death with the use of FFR-guided CABG as compared to CAG guided CABG (RR: $0.62,95 \%$ CI: 0.40 to $0.95, p=0.03$ ) (Figure 2A). The results of all 4 studies with a total of 1292 patients also showed that the rates of overall death were significantly lower in the FFR-guided CABG group (RR: $0.63,95 \%$ CI: 0.42 to $0.96, p=0.03$ ) (Figure 2A).

Major adverse cardiac and cerebrovascular events (MACCE)(double-arm randomised and observational studies)

Comparing the data of two randomised control studies ${ }^{12,13}$ with a total of 269 patients, we noted no significant difference in the rates of MACCE associated with the use of FFR-guided CABG as compared to CAG-guided CABG (RR: $0.89,95 \%$ CI: 0.41 to $1.94, p=0.77$ ) (Figure 2B). Data analysis of two observational studies ${ }^{14,15}$ and 1023 patients showed no significant difference in the rates of MACCE with the use of FFR-guided CABG or CAG-guided CABG (RR: 0.85, 95\% CI: 0.64 to 1.12, $p=0.25$ ) (Figure 2B). The results of all four studies with a total of 1292 patients ultimately showed no difference in the rates of MACCE in the FFR-guided CABG group as compared to the conventional CAG-guided CABG group (RR: 0.85, 95\% CI: 0.65 to 1.11, $p=0.23)$ (Figure 2B).

\section{Target vessel revascularisation (double-arm randomised and observational studies)}

In the 2 randomised control studies ${ }^{12,13}$ with a total of 269 patients, we saw no significant difference in the rates of target vessel revascularisation associated with the use of FFR-guided CABG as compared to CAGguided CABG. (RR: 0.70, 95\% CI: 0.23 to $2.19, p=0.54$ ) (Figure $3 \mathrm{C}$ ). In the 2 observational studies ${ }^{14,15}$ 
and 1023 patients we again noted no significant difference with the use of FFR-guided CABG as compared to CAG-guided CABG. (RR: 1.23, 95\% CI: 0.73 to 2.06, $p=0.43$ ) (Figure 3C). Ultimately, analysis of all 4 studies with a total of 1292 patients showed no difference between the FFR-guided CABG group as compared to the conventional CAG-guided CABG group (RR: 1.12, 95\% CI: 0.70 to 1.79, $p=0.73$ ) (Figure $3 \mathrm{C})$.

\section{Spontaneous myocardial infarction (double-arm randomised and observational studies)}

Comparing the results of two randomised control studies ${ }^{12,13}$ with a total of 269 patients, we noted no significant difference in the rates of spontaneous MI associated with the use of FFR-guided CABG vs. CAG-guided CABG. (RR: 0.70, 95\% CI: 0.08 to $6.25, p=0.75$ ) (Figure 3D). Data analysis of 2 observational studies ${ }^{14,15}$ and 1023 patients showed again no significant difference in the need of target vessel revascularisation with the use of either FFR-guided CABG or CAG-guided CABG (RR: 0.77, 95\% CI: 0.47 to $1.25, p=0.29$ ) (Figure 3D). Likewise in all four studies with a total of 1292 patients, there was no difference in the rates of spontaneous MI in the FFR-guided CABG group and the CAG-guided CABG group (RR: 0.77, 95\% CI: 0.48 to $1.23, p=0.27$ ) (Figure $3 \mathrm{D}$ ).

\section{Total number of grafts occluded (double-arm randomised and observational studies)}

Comparing the results of 2 randomised control studies ${ }^{12,13}$ with a total of 493 vessels evaluated by angiographic follow up, we noted no significant difference in the rates of graft occlusion between the two groups (RR: $1.05,95 \%$ CI: 0.72 to $1.54, p=0.79$ ) (Figure $4 \mathrm{E}$ ). Only one observational study ${ }^{15}$ reported the findings of angiographic evaluation of the grafts. With a total of 234 grafts evaluated in this study, there was significantly lower overall graft occlusion rates in the FFR-guided CABG as compared to CAG-guided CABG. (RR: $0.24,95 \%$ CI: 0.08 to $0.76, p=0.01$ ) (Figure 4E). However, due to only one study reporting a significant difference, the effect was not large enough to demonstrate a significant result overall, and in the analysis of all 3 studies, with a total of 727 patients, we observed no difference in the rates of graft occlusion between the FFR-guided and CAG-guided groups (RR: 0.81, 95\% CI: 0.57 to 1.15, p=0.24) (Figure 4E).

Arterial grafts occluded (double-arm randomised and observational studies)

Comparing the results of 2 randomised control studies ${ }^{12,13}$ with a total of 189 arterial grafts evaluated by angiographic follow up, we noted no significant difference in the rates graft occlusion between the two groups (RR: $1.00,95 \%$ CI: 0.59 to $1.72, p=0.99$ ) (Figure $4 \mathrm{~F}$ ). Only 1 observational study ${ }^{15}$ with a total of 157 grafts assessed angiographically showed no significant difference in graft occlusion rates between the two groups (RR: 0.29, 95\%CI: 0.07 to 1.20, $p=0.09$ ) (Figure 4F). The overall results of three studies with a total of 346 arterial grafts assessed also showed no intergroup difference in graft occlusion rates (RR: 0.77, 95\% CI: 0.47 to $1.28, p=0.31$ ) (Figure $4 \mathrm{~F}$ ).

Venous grafts occluded (double arm randomised control studies)

Analysis of the data of 2 randomised controlled studies ${ }^{12,13}$, and a total of 175 venous grafts that were angiographically assessed showed no significant intergroup difference in venous graft occlusion rates (RR: 1.347, $95 \%$ CI: 0.75 to $2.39, p=0.33$ ) (Figure 5).

Pooled rates of overall death, spontaneous myocardial infarction and target vessel revascularisation [four double-arm studies (two randomised and two observational) and two single-arm studies]

By carrying out a pooled analysis in the data of all six studies (two randomised ${ }^{12,13}$, two double-arm observational $^{14,15}$ and two single-armed ${ }^{16,17}$ ) we noted that FFR-guided CABG was associated with lower overall death rates as compared to CAG-guided CABG 6.1\% [95\% CI: 3.2\% - 9.7\%] (Figure 6A) vs 7.1\% [95\% CI: 2.8\% - 13.1\%] (Figure 6B). However, the rate of overall death in the CAG-guided CABG had a considerable risk of heterogeneity $\left(\mathrm{I}^{2}=82.52 \%, P<0.001\right)$. FFR-guided CABG also showed lower rates of spontaneous MI as compared to CAG-guided CABG 2.5\% [95\% CI: 0.9\% - 4.9\%] (Figure 7A), vs 5.0\% [95\% CI: $2.2 \%-8.8 \%$ ] (Figure 7B). FFR-guided CABG showed greater rates of target vessel revascularisation $6.8 \%$ [95\% CI: $3.5 \%-11.0 \%$ ] (Figure 8A), vs $4.9 \%$ [95\% CI: $2.6 \%-7.8 \%$ ] (Figure 8B). 


\section{Discussion}

The use of CAG relies on visual estimation to determine if the coronary arteries are in need of surgical revascularisation. This typically involves gauging the extent of the stenosis and the appearance of the lesion, which is often subject to the preference and possibly bias of the physician ${ }^{20}$. Using the irregularities observed in diseased coronary arteries, the degree of stenosis of the coronary vessels is quantified as a percentage and used as a basis of classification of the lesion into three categories: mild, intermediate or severe ${ }^{21,22}$. Intermediate coronary stenoses fall into a "grey zone", where the decision of what intervention is used and if an intervention is needed at all can become difficult ${ }^{20}$. The FFR is thus a useful tool in quantifying the degree of vessel narrowing to better assess coronary arteries with intermediate-stenosis ${ }^{23,24}$. Previously, research compared the outcomes of FFR-guided PCI versus conventional CAG-guided $\mathrm{PCI}^{25}$, showing that FFR was useful in guiding the use of percutaneous interventions and particularly so when the target vessel stenosis was in the order of [?]0.8026. However, the role and scope of the use of FFR in guiding CABG has yet to be determined ${ }^{14,27}$.

To the best of our knowledge, this is the first systematic review and meta-analysis comparing the clinical outcomes of FFR and CAG for the use of CABG. In this meta-analysis the use of FFR was associated with significantly less overall death than CAG-guided CABG surgeries. These results were also observed in our pooled analysis of overall death rates, which demonstrated an average of $6.1 \%$ for the FFR cohort, as compared to $7.1 \%$ for the CAG cohort. In the subgroup analyses of overall death rates, however, we noted that a significant difference was present solely in the two retrospective double-arm studies ${ }^{14,15}$. Hence, there is a need for further randomised controlled trials to investigate whether the use of FFR to guide CABG can lead to lower overall death rates.

Apart from lower rates of overall death, the results from the pooled analysis also showed a lower rate of spontaneous MI in the FFR cohort (2.5\%) as compared to the CAG cohort (5.0\%). Fournier et. al. ${ }^{14}$ has previously described the presence of a linear relation between the number of vein grafts used and the incidence of spontaneous MI and overall death and suggested that the significantly higher number of vein grafts used in CAG-guided CABG group was responsible for the observed higher incidence of MI and death ${ }^{14}$ (Table 3). On the other hand, in the study of Toth et. al. ${ }^{15}$ the FFR and CAG groups were linked with similar rates of spontaneous MI and death despite the use of a significantly higher number of vein grafts (and significantly lower number of arterial grafts) in the CAG group (Table 3).

In any case, the positive effect of the FFR on the occurrence of spontaneous MI seen in our pooled analysis was not present in our meta-analysis, where there were no significant difference in the rates of spontaneous MIs between the two groups. Once again, whether there truly is an association between the use of FFR and the probability of occurrence of spontaneous MI needs to be determined in future studies.

Graft occlusion was seen to be lower in FFR guided group in the retrospective study by Toth et $\mathrm{al}^{15}$, however on meta-analysis, there was no statistically significant difference between the two study groups (Figure 4E). Likewise, our meta-analysis did not reveal any statistically significant difference in the remaining primary and/or secondary end points of MACCE and target vessel revascularisation between the FFR and CAG guided CABG groups.

\section{Conclusion}

In this study, FFR-guided CABG is associated with decreased rates of overall death when compared to CAGguided CABG. Additionally, use of FFR is associated with non-inferior clinical outcomes when compared to the use of CAG, including rates of MACCE, target vessel revascularization, spontaneous MI and graft patency. Further randomized controlled trials are needed to better clarify the role of FFR in guiding CABG surgery.

\section{Acknowledgements}

None. 


\section{Declaration of conflicting interests}

The Authors declare that there is no conflict of interest.

\section{Author contributions}

Dhayan Timbadia

Contributed significantly to the Data analysis/interpretation and drafting of article

Ashlynn Ler

Contributed significantly to the Data analysis and interpretation and drafting of article

Faizus Sazzad

Contributed significantly to the Literature review and Critical revision of the article

Christos Alexiou

Contributed significantly to the Critical revision of the article

Theo Kofidis

Contributed significantly to the Approval of article and concept and design of article

\section{References}

1. Alexander JH, Smith PK. Coronary-Artery Bypass Grafting. New England Journal of Medicine. 2016;374(20):19541964.

2. Pijls NHJ, de Bruyne B, Peels K, et al. Measurement of Fractional Flow Reserve to Assess the Functional Severity of Coronary-Artery Stenoses. New England Journal of Medicine.1996;334(26):1703-1708.

3. Hachamovitch R, Berman DS, Shaw LJ, et al. Incremental Prognostic Value of Myocardial Perfusion Single Photon Emission Computed Tomography for the Prediction of Cardiac Death: Differential Stratification for Risk of Cardiac Death and Myocardial Infarction. Circulation.1998;97(6):535-543.

4. Pijls NHJ, Fearon WF, Tonino PAL, et al. Fractional flow reserve versus angiography for guiding percutaneous coronary intervention in patients with multivessel coronary artery disease : 2-year follow-up of the FAME (fractional flow reserve versus angiography for multivessel evaluation) study. Journal of the American College of Cardiology.2010;56(3):177-184.

5. Puymirat E, Peace A, Mangiacapra F, et al. Long-Term Clinical Outcome After Fractional Flow ReserveGuided Percutaneous Coronary Revascularization in Patients With Small-Vessel Disease.Circulation: Cardiovascular Interventions. 2012;5(1):62-68.

6. Botman CJMD, Schonberger JMDP, Koolen SMDP, et al. Does Stenosis Severity of Native Vessels Influence Bypass Graft Patency? A Prospective Fractional Flow Reserve-Guided Study. The Annals of Thoracic Surgery. 2007;83(6):2093-2097.

7. Harskamp RE, Alexander JH, Ferguson TB, Jr., et al. Frequency and Predictors of Internal Mammary Artery Graft Failure and Subsequent Clinical Outcomes: Insights From the Project of Ex-vivo Vein Graft Engineering via Transfection (PREVENT) IV Trial. Circulation.2016;133(2):131-138.

8. Moher D, Liberati A, Tetzlaff J, Altman DG. Preferred reporting items for systematic reviews and meta-analyses: the PRISMA statement.Ann Intern Med. 2009;151(4):264-269, w264.

9. Cochrane GRADEing Methods Group (formerly Applicability and Recommendations Methods Group) and the Cochrane Statistical Methods Group. Completing 'Summary of findings' tables and grading the certainty of the evidence. Cochrane Handbook for Systematic Reviews of Interventions. . 2019 Sep

10. RevMan R. The nordic cochrane centre tcc. 
11. Wallace BC, Dahabreh IJ, Trikalinos TA, Lau J, Trow P, Schmid CH. Closing the gap between methodologists and end-users: R as a computational back-end. J Stat Softw. 2012;49(5):1-15.

12. Toth GG, De Bruyne B, Kala P, et al. Graft patency after FFR-guided versus angiography-guided coronary artery bypass grafting: the GRAFFITI trial. Eurointervention. 2019;15(11):E999-+.

13. Thuesen AL, Riber LP, Veien KT, et al. Fractional Flow Reserve Versus Angiographically-Guided Coronary Artery Bypass Grafting. J Am Coll Cardiol. 2018;72(22):2732-2743.

14. Fournier S, Toth GG, De Bruyne B, et al. Six-Year Follow-Up of Fractional Flow Reserve-Guided Versus Angiography-Guided Coronary Artery Bypass Graft Surgery. Circ Cardiovasc Interv. 2018;11(6):e006368.

15. Toth G, De Bruyne B, Casselman F, et al. Fractional flow reserve-guided versus angiography-guided coronary artery bypass graft surgery. Circulation. 2013;128(13):1405-1411.

16. Muller O, Mangiacapra F, Ntalianis A, et al. Long-Term Follow-Up After Fractional Flow ReserveGuided Treatment Strategy in Patients With an Isolated Proximal Left Anterior Descending Coronary Aden, Stenosis. Jacc-Cardiovascular Interventions. 2011;4(11):1175-1182.

17. Hamilos M, Muller O, Cuisset T, et al. Long-term clinical outcome after fractional flow reserveguided treatment in patients with angiographically equivocal left main coronary artery stenosis. Circulation. 2009;120(15):1505-1512.

18. Mansour S, El Hammiri A, Matteau A, et al. APPROPRIATENESS OF CORONARY ARTERY BYPASS GRAFTING BASED ON FRACTIONAL FLOW RESERVE LESIONS ASSESSMENT. Journal of the American College of Cardiology.2017;69(11):1061-1061.

19. Van Belle E, Rioufol G, Pouillot C, et al. Outcome Impact of Coronary Revascularization Strategy Reclassification With Fractional Flow Reserve at Time of Diagnostic Angiography Insights From a Large French Multicenter Fractional Flow Reserve Registry. Circulation.2014;129(2):173-185.

20. Hill D, Lim MJ. Fractional Flow Reserve. In: StatPearls.Treasure Island (FL): StatPearls Publishing StatPearls Publishing LLC.; 2020.

21. Lee JM, Choi KH, Koo BK, et al. Prognostic Implications of Plaque Characteristics and Stenosis Severity in Patients With Coronary Artery Disease. J Am Coll Cardiol. 2019;73(19):2413-2424.

22. Demir OM, Mitomo S, Mangieri A, et al. Diagnostic Accuracy of Microcatheter Derived Fractional Flow Reserve. Am J Cardiol.2019;124(2):183-189.

23. Whayne TF, Jr., Sousa MJ, Abdel-Latif A. Use and Value of Fractional Flow Reserve in Coronary Arteriography. Angiology.2020;71(1):5-9.

24. Masdjedi K, van Zandvoort LJC, Balbi MM, et al. Validation of 3-Dimensional Quantitative Coronary Angiography based software to calculate Fractional Flow Reserve: Fast Assessment of STenosis severity (FAST)-study. EuroIntervention. 2019.

25. Pijls NH, Fearon WF, Tonino PA, et al. Fractional flow reserve versus angiography for guiding percutaneous coronary intervention in patients with multivessel coronary artery disease: 2-year follow-up of the FAME (Fractional Flow Reserve Versus Angiography for Multivessel Evaluation) study. J Am Coll Cardiol. 2010;56(3):177-184.

26. De Bruyne B, Pijls NH, Kalesan B, et al. Fractional flow reserve-guided PCI versus medical therapy in stable coronary disease. $N$ Engl J Med. 2012;367(11):991-1001.

27. Ahmadi A, Stanger D, Puskas J, Taggart D, Chandrashekhar Y, Narula J. Is there a role for fractional flow reserve in coronary artery bypass graft (CABG) planning? Ann Cardiothorac Surg. 2018;7(4):546-551. 


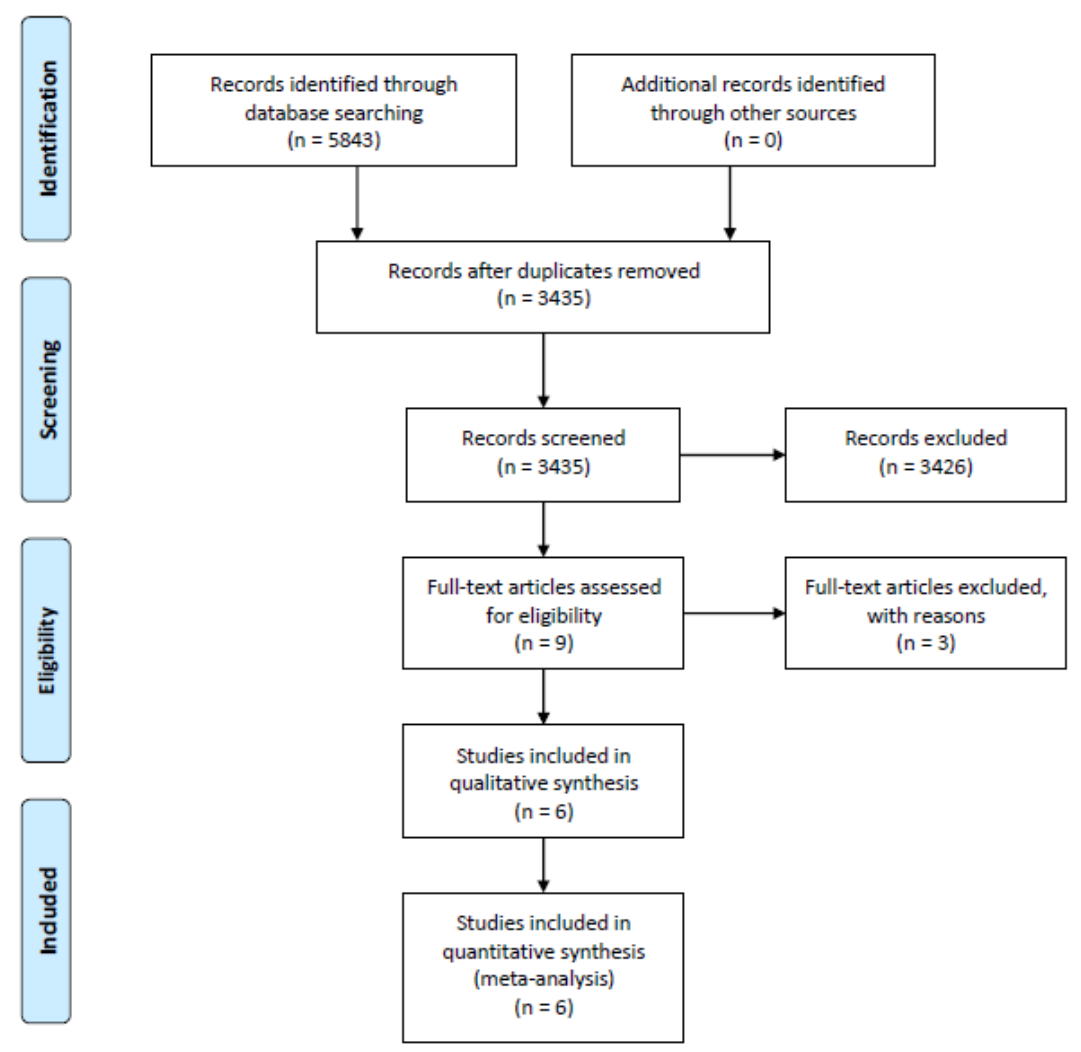

From: Moher D, Liberati A, Tetzlaff J, Altman DG, The PRISMA Group (2009). Preferred Reporting Items for Systematic Reviews and MetaAnalyses: The PRISMA Statement. PLoS Med 6(7): e1000097. doi:10.1371/journal.pmed 1000097

For more information, visit www.prisma-statement.org.

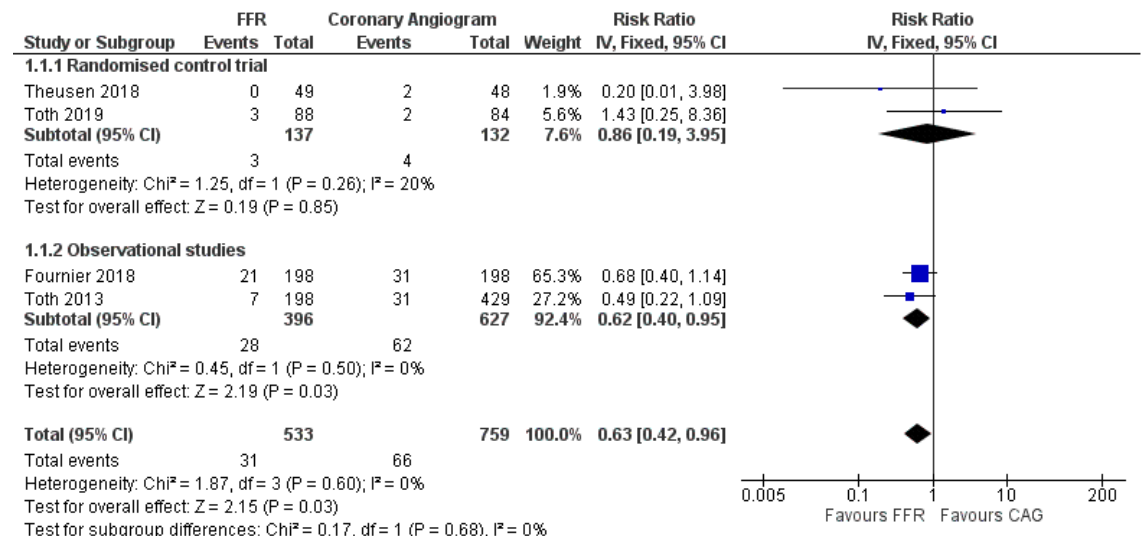




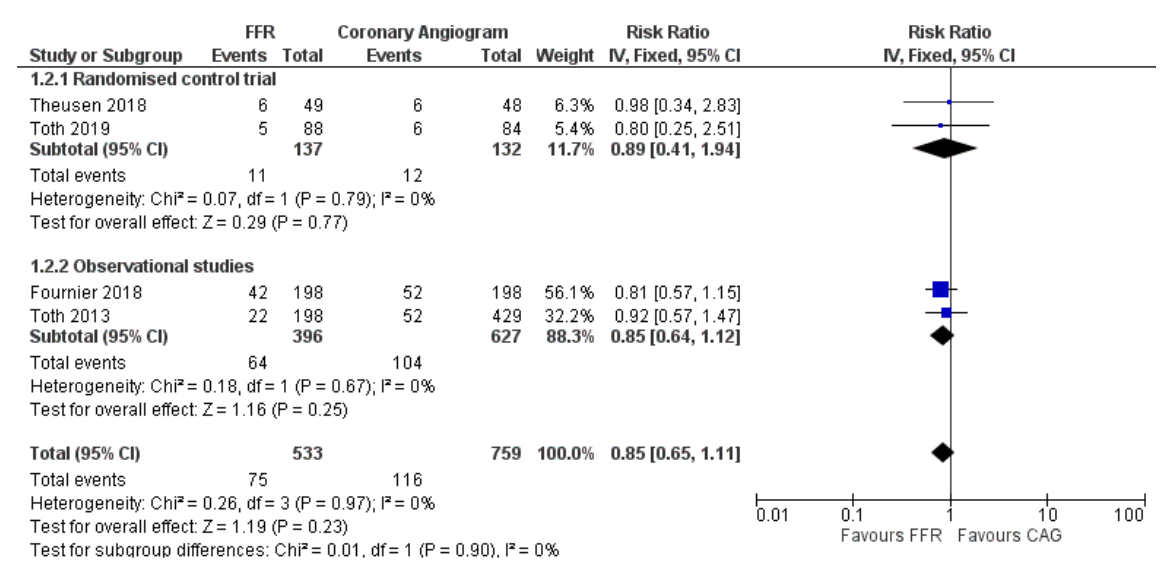

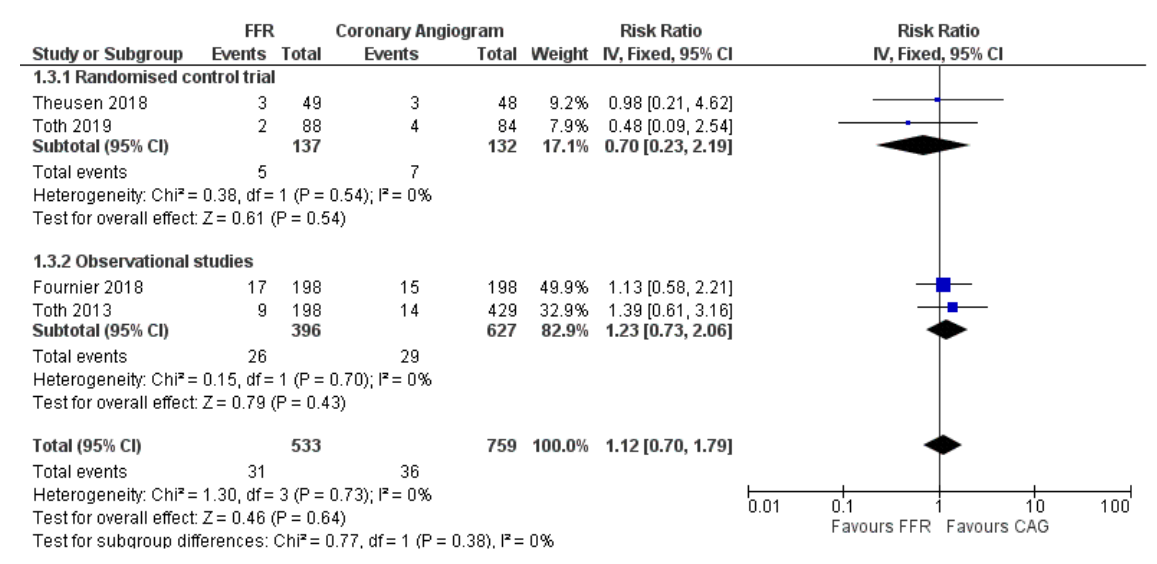

\begin{tabular}{|c|c|c|c|c|c|c|c|c|c|c|}
\hline Study or Subgroup & \multicolumn{2}{|l|}{ FFR } & \multicolumn{2}{|c|}{ Coronary Angiogram } & Weight & $\begin{array}{l}\text { Risk Ratio } \\
\text { IV, Fixed, } 95 \% \mathrm{Cl}\end{array}$ & \multicolumn{4}{|c|}{$\begin{array}{c}\text { Risk Ratio } \\
\text { IV, Fixed, } 95 \% \mathrm{Cl}\end{array}$} \\
\hline \multicolumn{10}{|c|}{ 1.4.1 Randomised control trial } & \\
\hline Theusen 2018 & 1 & 49 & 0 & 48 & $2.2 \%$ & $2.94[0.12,70.43]$ & & & & \\
\hline Toth 2019 & 0 & 88 & 2 & 84 & $2.5 \%$ & $0.19[0.01,3.92]$ & & & & \\
\hline Subtotal $(95 \% \mathrm{Cl})$ & & 137 & & 132 & $4.7 \%$ & $0.70[0.08,6.25]$ & & & & \\
\hline Total events & 1 & & 2 & & & & & & & \\
\hline \multicolumn{11}{|c|}{$\begin{array}{l}\text { Heterogeneity: } \mathrm{Chi}^{2}=1.49, \mathrm{df}=1(\mathrm{P}=0.22) ; \mathrm{I}^{2}=33 \% \\
\text { Test for overall effect: } Z=0.32(P=0.75)\end{array}$} \\
\hline \multicolumn{11}{|c|}{ 1.4.2 Observational study } \\
\hline Fournier 2018 & 11 & 198 & 20 & 198 & $44.8 \%$ & $0.55[0.27,1.12]$ & & & & \\
\hline $\begin{array}{l}\text { Toth } 2013 \\
\text { Subtotal }(95 \% \mathrm{Cl})\end{array}$ & 12 & $\begin{array}{l}198 \\
396\end{array}$ & 25 & $\begin{array}{l}429 \\
627\end{array}$ & $\begin{array}{l}50.5 \% \\
95.3 \%\end{array}$ & $\begin{array}{l}1.04[0.53,2.03] \\
\mathbf{0 . 7 7}[\mathbf{0 . 4 7}, \mathbf{1 . 2 5}]\end{array}$ & & & & \\
\hline & 23 & & & & & & & & & \\
\hline \multicolumn{11}{|c|}{$\begin{array}{l}\text { Heterogeneity: } \mathrm{Chi}^{2}=1.64, \mathrm{df}=1(\mathrm{P}=0.20) ; \mathrm{I}^{2}=39 \% \\
\text { Test for overall effect: } Z=1.05(P=0.29)\end{array}$} \\
\hline Total $(95 \% \mathrm{Cl})$ & & 533 & & 759 & $100.0 \%$ & $0.77[0.48,1.23]$ & & & & \\
\hline Total events & 24 & & 47 & & & & & & & \\
\hline $\begin{array}{l}\text { Heterogeneity: } \mathrm{Chi}^{2}= \\
\text { Test for overall effect } \\
\text { Test for subqroup di }\end{array}$ & $\begin{array}{l}3.15, d f= \\
Z=1.09 \\
\text { erences: }\end{array}$ & $\begin{array}{l}3(P= \\
P=0.2 \\
C^{2}{ }^{2}=0\end{array}$ & $\begin{array}{l}37) ;\left.\right|^{2}=5 \% \\
01, d f=1(P\end{array}$ & & & & 0.002 & $\begin{array}{c}0.1 \\
\text { Favours FFR }\end{array}$ & $\begin{array}{c}10 \\
10 \\
\text { Favours CAG }\end{array}$ & 500 \\
\hline
\end{tabular}




\begin{tabular}{|c|c|c|c|c|c|c|c|c|c|c|}
\hline Study or Subgroup & \multicolumn{2}{|l|}{ FFR } & \multicolumn{2}{|c|}{ Coronary Angiogram } & Weight & $\begin{array}{l}\text { Risk Ratio } \\
\text { M-H, Fixed, } 95 \% \mathrm{Cl}\end{array}$ & \multicolumn{4}{|c|}{$\begin{array}{c}\text { Risk Ratio } \\
\text { M-H, Fixed, } 95 \% \mathrm{Cl}\end{array}$} \\
\hline \multicolumn{11}{|c|}{ 2.1.1 Randomised control trial } \\
\hline Theusen 2018 & 15 & 94 & 13 & 100 & $20.6 \%$ & $1.23[0.62,2.44]$ & & & & \\
\hline Toth 2019 & 28 & 141 & 32 & 158 & $49.3 \%$ & $0.98[0.62,1.54]$ & & & & \\
\hline Subtotal (95\% Cl) & & 235 & & 258 & $69.9 \%$ & $1.05[0.72,1.54]$ & & & & \\
\hline \multirow{3}{*}{\multicolumn{11}{|c|}{$\begin{array}{l}\text { Heterogeneity: } \mathrm{Chi}^{2}=0.29, \mathrm{df}=1(P=0.59) ; I^{2}=0 \% \\
\text { Test for overall effect: } Z=0.27(P=0.79)\end{array}$}} \\
\hline & & & & & & & & & & \\
\hline & & & & & & & & & & \\
\hline \multicolumn{11}{|c|}{ 2.1.2 Observational studies } \\
\hline Toth 2013 & 3 & 60 & 36 & 174 & $30.1 \%$ & $0.24[0.08,0.76]$ & & & & \\
\hline Subtotal $(95 \% \mathrm{Cl})$ & & 60 & & 174 & $30.1 \%$ & $0.24[0.08,0.76]$ & & & & \\
\hline Total events & 3 & & 36 & & & & & & & \\
\hline \multirow{2}{*}{\multicolumn{11}{|c|}{$\begin{array}{l}\text { Heterogeneity: Not applicable } \\
\text { Test for overall effect: } Z=2.44(P=0.01)\end{array}$}} \\
\hline & & & & & & & & & & \\
\hline Total $(95 \% \mathrm{Cl})$ & & 295 & & 432 & $100.0 \%$ & $0.81[0.57,1.15]$ & & 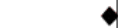 & & \\
\hline Total events & 46 & & 81 & & & & & & & \\
\hline $\begin{array}{l}\text { Heterogeneity: } \mathrm{Ch}^{2} \\
\text { Test for overall effec }\end{array}$ & $\begin{array}{l}6.42, d f= \\
Z=1.17\end{array}$ & $\begin{array}{l}2(P=0 \\
P=0.2\end{array}$ & $0.04) ;\left.\right|^{2}=69 \%$ & & & & 0.001 & 0.1 & $1 \quad 10$ & $\overrightarrow{1000}$ \\
\hline Test for subqroup d & ferences: & $\mathrm{Ch}^{2}=5$ & & $\left.\right|^{2}$ & & & & & & \\
\hline
\end{tabular}

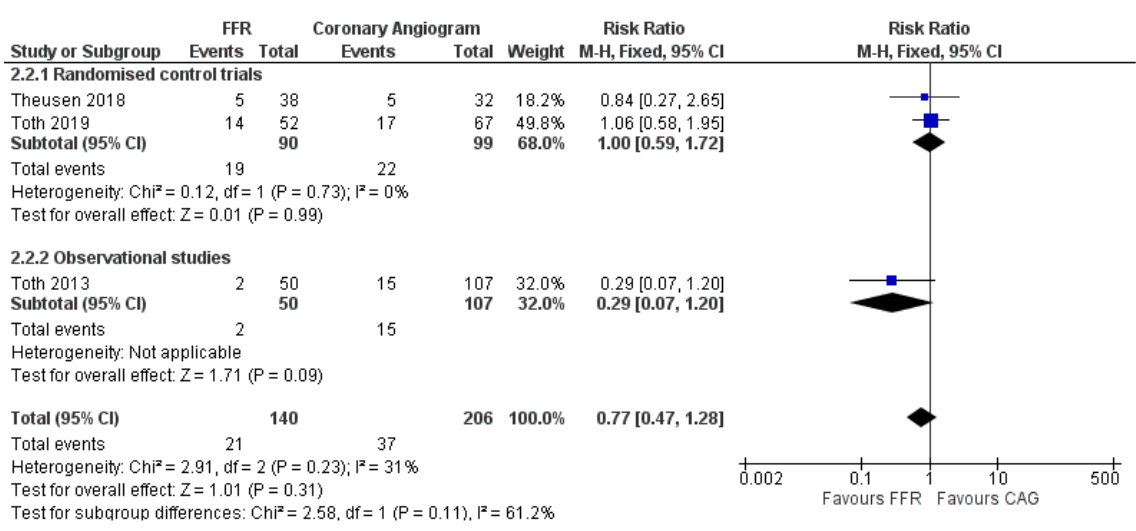

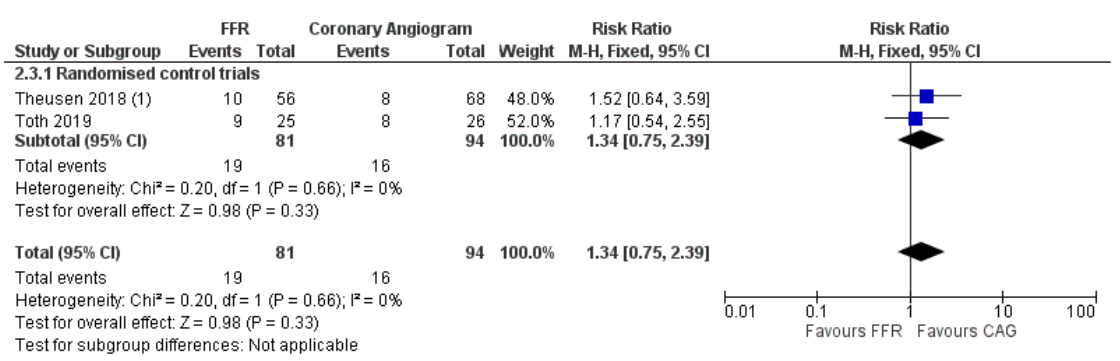

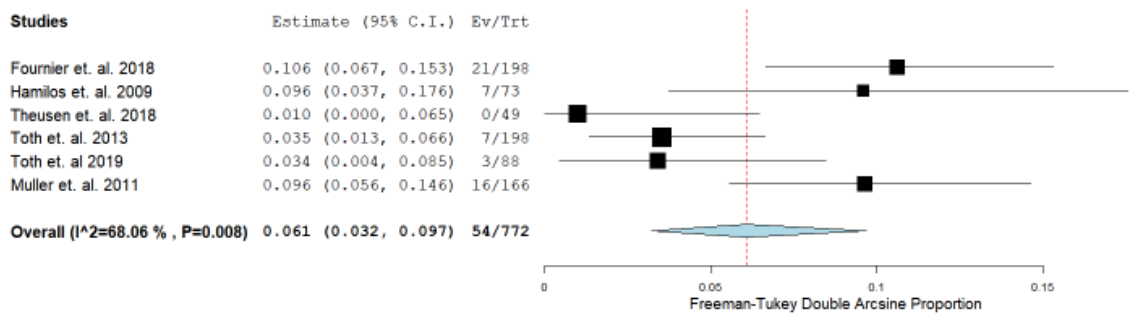


Studies

Fournier et. al. 2018 Theusen et. al. 2018 Toth et. al. 2013 Toth et. al 2019

Overall $\left(\left.\right|^{\wedge} 2=82.52 \%, P<0.001\right) \quad 0.071 \quad(0.028,0.131) \quad 66 / 759$

Estimate (95\% C.I.) Ev/Trt

$0.157(0.109,0.211) 31 / 198$ $0.042(0.001,0.121) \quad 2 / 48$ $0.072(0.050,0.099) 31 / 429$

$0.024(0.000,0.070) \quad 2 / 84$

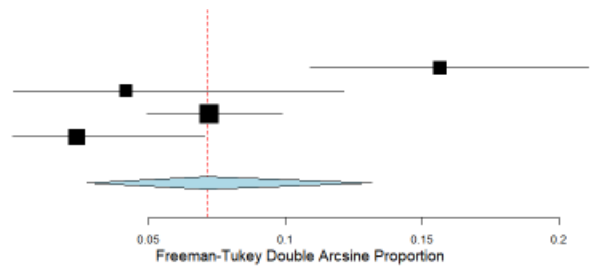

Studies

Fournier et. al. 2018 Hamilos et. al. 2009 Theusen et. al. 2018 Toth et. al. 2013 Toth et al 2019 Muler at a. 2011 Muller et. al. 2011

Overall ( ॥ $2=61.73 \%, P=0.023) \quad 0.025(0.009,0.049) \quad 26 / 771$

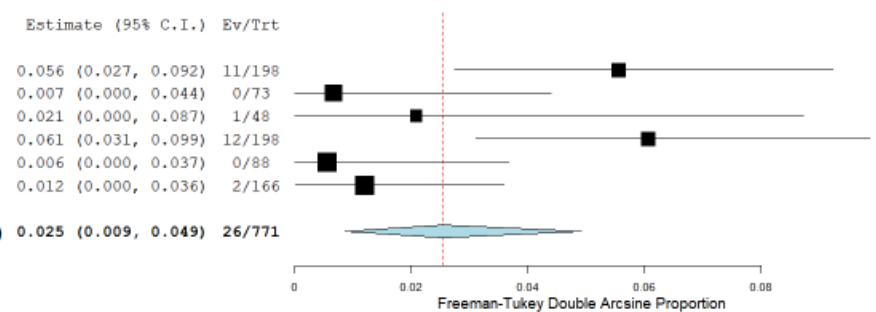

Studies

Fournier et. al. 2018 Theusen et. al. 2018 Toth et. al. 2013 Toth et. al 2019 Overall (1^2=67.74\%, $P=0.026) \quad 0.050 \quad(0.022,0.088) \quad 47 / 759$ Estimate (95\% C.I.) Ev/Trt $0.101(0.063,0.147) \quad 20 / 198$ $0.010(0.000,0.066) \quad 0 / 48$ $0.058(0.038,0.083) \quad 25 / 429$ $0.024(0.000,0.070) 2 / 84$
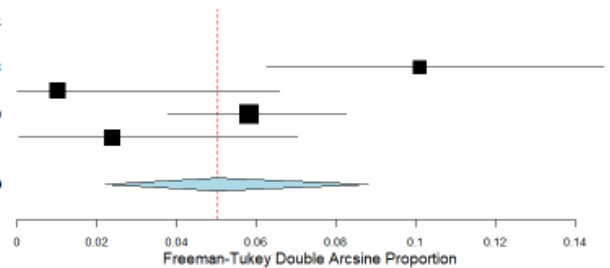

Studies

Fournier et. al. 2018 Hamilos et. al. 2009 Theusen et at. 2018 Theusen et. al. 2018 Toth et. al. 2013 Toth et. al 2019 Muller et. al. 2011 Overall $(1 \wedge 2=73.94 \%, P=0.002) \quad 0.068(0.035,0.110) \quad 61 / 772$ Estimate (95\% C.I.) Ev/Trt $0.086(0.050,0.129) \quad 17 / 198$ $0.055(0.012,0.121) \quad 4 / 73$ $0.061(0.008,0.149) \quad 3 / 49$ $0.045(0.020,0.080) \quad 9 / 198$ $0.023(10.0200,0.087)-9 / 98$ $0.157(0.105,0.216) 26 / 166$

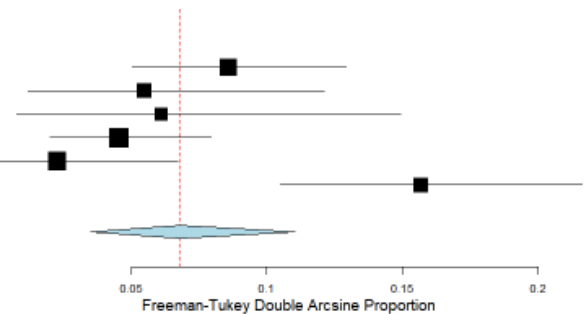

Studies

Fournier et. al. 2018 Theusen et. al. 2018 Toth et. al. 2013 Toth et. al 2019

Estimate (95\% C.I.) Ev/Trt

$0.076(0.043,0.117) \quad 15 / 198$ $0.062(0.008,0.152) \quad 3 / 48$ $0.033(0.018,0.052) 14 / 429$ $0.048(0.010,0.106) \quad 4 / 84$

Overall $(1 \wedge 2=48.33 \%, P=0.121) \quad 0.049(0.026,0.078) \quad 36 / 759$

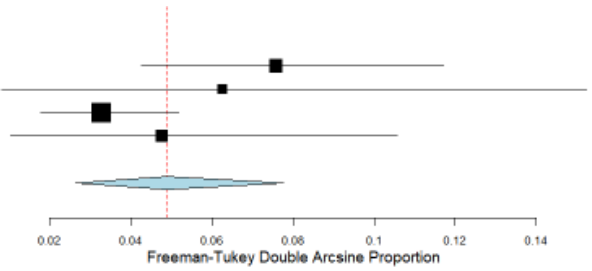

\section{Hosted file}

Table 1.docx available at https://authorea.com/users/316017/articles/446244-ffr-guided-versuscoronary-angiogram-guided-cabg-a-systematic-review-and-meta-analysis

\section{Hosted file}

Table 2.docx available at https://authorea.com/users/316017/articles/446244-ffr-guided-versuscoronary-angiogram-guided-cabg-a-systematic-review-and-meta-analysis 


\section{Hosted file}

Table 3.docx available at https://authorea.com/users/316017/articles/446244-ffr-guided-versuscoronary-angiogram-guided-cabg-a-systematic-review-and-meta-analysis 